\title{
Neuroprotective effect of Atractylodes macrocephalaon polysaccharides in vitro on neuronal apoptosis induced by hypoxia
}

\author{
WEI-XU HU ${ }^{1}$, QIN XIANG ${ }^{2,4}$, ZHU WEN ${ }^{3}$, DAN HE ${ }^{2}$, XIAO-MU WU ${ }^{2}$ and GUO-ZHU HU ${ }^{2}$ \\ ${ }^{1}$ Department of Radiation Oncology, Zhongshan Hospital, Fudan University, Shanghai 200032; \\ ${ }^{2}$ Institute of Clinical Medicial Sciences, The People's Hospital of Jiangxi Province; \\ ${ }^{3}$ Department of Hematology, Jiangxi Academy of Medical Science, Nanchang, Jiangxi 330006; \\ ${ }^{4}$ College of Biology, Hunan University, Changsha, Hunan 410082, P.R. China
}

Received July 25, 2013; Accepted March 4, 2014

DOI: $10.3892 / \mathrm{mmr} .2014 .2105$

\begin{abstract}
Rhizoma Atractylodis macrocephalae have an important role in treating cerebrovascular diseases in Traditional Chinese Medicine (TCM). The purpose of the present study was to determine the neuroprotective effect of Atractylodis macrocephalaon polysaccharides (AMPS) on hypoxia-induced apoptosis of cerebral cortical neurons. Neuronal cells obtained from neonatal rats were divided into the following groups: Normal control (group C); apoptosis positive induced by hypoxia-reoxygenation culture of rat primary cerebral cortical neurons (group A); treated with $0.025 \mathrm{~g} / 1$ AMPS prior to hypoxia culture of neurons $\left(\mathrm{AMPS}_{1}\right)$; treated with $0.05 \mathrm{~g} / 1$ AMPS $\left(\mathrm{AMPS}_{2}\right)$; treated with $0.1 \mathrm{~g} / 1 \mathrm{AMPS}$ $\left(\mathrm{AMPS}_{3}\right)$; and treated with $0.25 \mathrm{~g} / \mathrm{l} \mathrm{AMPS}\left(\mathrm{AMPS}_{4}\right)$. Neuronal apoptosis was examined with Annexin V-fluorescein isothiocyanate/propidium iodide, Hoechst 33342 fluorescent staining, Rhodamine 123 staining, polymerase chain reaction assay and immunocytochemical staining. The results showed that the AMPS significantly prevented the growth inhibition, mitochondrial injury and apoptosis of neurons induced by hypoxia. The levels of Caspase-3 and Bax mRNAs and proteins were significantly downregulated by AMPS in neurons exposed to hypoxia, and the levels of B-cell lymphoma 2 (Bcl-2) protein was significantly upregulated by AMPS in neurons exposed to hypoxia, as compared with group $\mathrm{A}(\mathrm{P}<0.05)$. The ratio of $\mathrm{Bcl}-2 / \mathrm{Bcl}-2$-associated $\mathrm{X}$ protein (Bax) mRNA and protein was significantly increased by AMPS in neurons exposed to hypoxia as compared with group A $(\mathrm{P}<0.05)$. The observed improved neuronal growth and inhibition neuronal apoptosis
\end{abstract}

Correspondence to: Professor Guo-zhu Hu, Institute of Clinical Medical Sciences, The People's Hospital of Jiangxi Province, 152 Ai Guo Road, Nanchang, Jiangxi 330006, P.R. China

E-mail: hgz56@126.com

Key words: apoptosis, hypoxia, in vitro, neurons, polysaccharides, Rhizoma Atractylodis macrocephalae by AMPS may be due to a decrease in the levels of Bax and Caspase- 3 and an increase in the levels of Bcl-2 and the ratio of Bcl-2/Bax in hypoxic neurons.

\section{Introduction}

In acute or chronic ischemia/hypoxia, necrosis and apoptosis of neurons may be caused. Traditional Chinese Medicine (TCM) possesses a unique advantage in this field due to comprehensive knowledge in the treatment of ischemic stroke. Notably, the prescriptions with the main drugs of rhizoma Atractylodis macrocephalae $(1,2)$, ginseng (3), Astragalus (4) and Polygonatum (5), Chinese herbs with qi-invigorating properties have great therapeutic benefit for treating ischemic stroke and vascular dementia (VD) in the recovery of neurological function. In TCM, Chinese herbs with the same drug properties possess an identical or similar drug efficacy.

Rhizoma Atractylodis macrocephalae is a herb which invigorates the spleen and supplements qi in the Chinese Pharmacopoeia and has a variety of pharmacological or physiological effects on the central nervous system. Atractylodes macrocephalaon polysaccharides (AMPS) are the active ingredients of the Chinese Herbal Medicine rhizoma Atractylodis macrocephalae. In a rat model of middle cerebral artery occlusion (MCAO), the neurological deficit scores and injured neurons in AMPS-treated groups were significantly lower and fewer compared with the MCAO group following administration of $4 \%$ AMPS solution (40 mg/kg b.w.) via femoral vein injection $(\mathrm{P}<0.05-0.01)$. AMPS markedly inhibited inducible nitric oxide synthase (iNOS) expression and alleviated brain edema in ischemic areas $(6,7)$. D-galactose-induced mimetic aging mice treated by intragastric administration with AMPS $(0.28 \mathrm{~g} / \mathrm{kg}$ b.w $/ \mathrm{d})$ exhibited significantly elevated levels of superoxide dismutase (SOD) and glutathione peroxidase (GSH-Px) as well as decreased levels of malondialdehyde (MDA) and DNA damage in the cerebral cortex neurons in rats (8). With intragastric administration of rhizoma Atractylodis macrocephalae decoction or AMPS to mice, learning ability and memory as well as SOD activity in the brains were significantly 
increased, while the contents of MDA and lipofuscin (LPF) in the brains were markedly decreased. However, the curative effect of a rhizoma Atractylodis macrocephalae decoction and AMPS did not exhibit marked differences (9).

Other qi-invigorating herbs and their active ingredients, including ginsenosides (10), Astragalus extract (11) and astragaloside IV (12), significantly attenuated terminal deoxynucleotidyl transferase dUTP nick end labeling-positive cells and levels of neuronal apoptosis caused by cerebral ischemia-reperfusion injury. The neuroprotective effect of these herbs may be based on marked increases of ATP and ADP levels, energy charge value, $\mathrm{Na}^{(+)}-\mathrm{K}^{(+)}$-ATPase, SOD activity and B-cell lymphoma 2 (Bcl-2) expression, as well as downregulation of the expression of phosphorylated c-Jun N-terminal kinase (p-JNK) $1 / 2$, cytochrome $C$ (cyt $C$ ), calpain I, Caspase-1, Caspase-9 and Caspase-3, and the MDA content and iNOS activity in rat and mice models of MCAO and bilateral common carotid artery occlusion (BCCAO). The ginsenoside $\mathrm{Rg} 2$ significantly improved neurological responses and memory ability, increased the expression of $\mathrm{Bcl}-2$ and heat shock protein (Hsp) 70 proteins and decreased the expression of Bax and $\mathrm{p} 53$ proteins in rats with vascular dementia (13). In mice administered with dexamethasone, the treatment with Astragalus extract significantly improved learning and memory, decreased the expression of Caspase-3 and cyt $C$ in the hippocampus and neocortex and inhibited the activity of Caspase-9 and Caspase-3 (14).

In vitro, a rhizoma Atractylodis macrocephalae extract significantly elevated the cell viability and reduced the number of apoptotic cells in glutamate excitotoxicity-induced neuronal apoptosis of primary cultured cerebral cortical neurons (15). The ginsenoside $\mathrm{Rg} 1$ is able to increase neuronal viability, reduce lactate dehydrogenase release and evade cell apoptosis induced by $\beta$-amyloid protein 25-35 [A $\beta$ (25-35)], as well as decrease the levels of Caspase- 3 and increase the ratio of $\mathrm{Bcl}-2 / \mathrm{Bax}$ in primary cultured rat hippocampal neuronal cells (16). Previous studies by our group have also demonstrated that polysaccharides from Polygonatum (17) and white hyacinth bean $(18,19)$, a qi-invigorating herb in TCM, added prior to hypoxia, showed activity against necrosis and apoptosis of neurons induced by hypoxia in rat primary cerebral cortical neuronal cells, significantly reduced the levels of Bax and Caspase-3 proteins and increased the levels of Bcl-2 protein and the ratio of $\mathrm{Bcl}-2 / \mathrm{Bax}$.

In the present study, the neuroprotective effect of AMPS on hypoxia-induced apoptosis of cerebral cortical neurons cultured in vitro was investigated. The study provided marked experimental evidence supporting the hypothesis that AMPS improves neuronal growth activity under hypoxia and inhibits apoptosis of neurons induced by hypoxia, which provides a theoretical basis for the reasonable administration for preventing and treating ischemic cerebral diseases and aging effects.

\section{Materials and methods}

Materials. Neurobasal medium and B-27 supplement were obtained from Gibco-BRL (Carlsbad, CA, USA). Equine serum, poly-D-lysine and trypsin were obtained from Sigma Chemical Co. (St. Louis, MO, USA). AMPS (purity, $>95.0 \%$ ) was obtained from Nanjing Zelang Medical Technological Co., Ltd.
(Nanjing, Jiangsu, China). Rabbit anti-rat neuron-specific enolase (NSE) polyclonal antibody was obtained from Wuhan Boster Bio-Engineering Co., Ltd. (Wuhan, Hubei, China). Rabbit anti-rat glial fibrillary acidic protein (GFAP), Bcl-2, Bax and Caspase-3 polyclonal antibodies and diaminobenzidine substrate kit were obtained from Beijing Zhong Sha Gold Bridge Bio-Technology Co., Ltd. (ZSGB-BIO, Beijing, China). An ABC-anti-rabbit immunoglobulin G (IgG) kit was obtained from Vector Laboratories, Inc. (Burlingame, CA, USA). Hoechst 33342, Annexin V-fluorescein isothiocyanate (FITC) and Rhodamine 123 staining detection kits were obtained from Nanjing KeyGen Biotech Co., Ltd. (Nanjing, Jiangsu, China). MTT was obtained from Beijing Probe Biotech Co., Ltd. (Beijing, China). TransScript ${ }^{\mathrm{TM}}$ two-step RT-PCR Supermix kit was obtained from Beijing TransGen Biotech Co., Ltd. (Beijing, China).

Animals. Sprague-Dawley rats (pregnant, 15-18 days) were bred and housed by the Laboratory Animal Services Centre of the Jiangxi college of Traditional Chinese Medicine (license key, SCXK (Jiangxi) 2005-0001). All experiments were performed in accordance with the animal experimental guidelines established by the Ministry of Science and Technology of the People's Republic of China and approved by the ethics committee of Jiangxi Province People's Hospital (Nanchang, China).

Primary serum-free culture of cerebral cortical neurons. The neuronal suspension was prepared from neonatal rats according to a previously described method (17). Cell suspension $\left(5 \times 10^{5} / \mathrm{ml}\right)$ was inoculated in 96,24 or six-well culture plates coated with poly-lysine. The culture plates were placed in a $\mathrm{CO}_{2}$ incubator (Thermo Fisher Scientific, Waltham, MA, USA) at $37^{\circ} \mathrm{C}, 5 \% \mathrm{CO}_{2}$ and saturated humidity for $4 \mathrm{~h}$. After $4 \mathrm{~h}$, the Dulbecco's modified Eagle medium (DMEM; Gibco-BRL) containing $10 \%$ equine serum was removed, and $2.0 \%$ B27 neurobasal medium was added to the cells for further culture. Half of culture medium was replaced after three days.

Cytotoxicity of AMPS on the cerebral cortical neurons in primary serum-free culture. Neuronal suspension $(0.1 \mathrm{ml}$ of $5 \times 10^{5} / \mathrm{ml}$ ) was inoculated in 96 -well culture plates coated with poly-lysine, and placed in an incubator at $37^{\circ} \mathrm{C}$ with $5 \% \mathrm{CO}_{2}$ and saturated humidity for $4 \mathrm{~h}$. After $4 \mathrm{~h}$, the DMEM containing $10 \%$ equine serum was removed, $2.0 \%$ B27 neurobasal medium was added to the cultured cells for further culture for 4 days, and $0.025,0.05,0.10,0.25,0.50$, $1.0,2.0$ or $4.0 \mathrm{~g} / 1$ AMPS was added to the cultured cells for a further $48 \mathrm{~h}$. Prior to termination of the neuronal culture, the culture media was removed, and $0.1 \mathrm{ml}$ culture media containing $0.5 \%$ MTT was added to the 96 -well plates prior to incubation for $4 \mathrm{~h}$. Next, the culture media was removed, $0.15 \mathrm{ml}$ dimethylsulfoxide (DMSO) was added to wells, the plates agitated for $10 \mathrm{~min}$ and the absorbance [optical density (OD) value] was detected at $490 \mathrm{~nm}$ wavelength by a microplate reader (ELX800; Labststems, Helsinki, Finland) (each group consisted of three wells).

Cytotoxicity of AMPS on the cerebral cortical neurons in primary serum-free hypoxia/reoxygenation culture. The neuron suspension $\left(0.1 \mathrm{ml}\right.$ of $\left.5 \times 10^{5} / \mathrm{ml}\right)$ was inoculated in 
96-well culture plates coated with poly-lysine and placed in an incubator at $37^{\circ} \mathrm{C}$ with $5 \% \mathrm{CO}_{2}$ and saturated humidity for $4 \mathrm{~h}$. After $4 \mathrm{~h}$, the DMEM containing 10\% equine serum was removed, $2.0 \%$ B27 neurobasal medium was added to the culture cells for a further 4 days, and $0.025,0.05,0.10$, $0.25,0.50$ or $1.0 \mathrm{~g} / 1$ AMPS was added to the cultured cells for a further $4 \mathrm{~h}$. The 96 -well culture plates were then placed into hypoxia culture $(85 \%$ nitrogen, $10 \%$ hydrogen and $5 \%$ carbon dioxide, at $37^{\circ} \mathrm{C}$; YQX-II, anaerobic system; Shanghai Hengyue Medical Instruments Co., Ltd, Shanghai, China) for $12 \mathrm{~h}$ and then placed in a $5 \% \mathrm{CO}_{2}$ incubator reoxygenation culture for $24 \mathrm{~h}$. Prior to termination of the neuron culture, the culture media was removed and $0.1 \mathrm{ml}$ culture media containing $0.5 \%$ MTT was added to the 96-well plates prior to incubation for $4 \mathrm{~h}$. Next, the culture media was removed, $0.15 \mathrm{ml}$ DMSO was added to the wells, plates were agitated for $10 \mathrm{~min}$ and the OD value was detected at $490 \mathrm{~nm}$ wavelength by a microplate reader.

Grouping. The animals were divided into the following groups: (i) Normal control (group C); 5x10 $/ \mathrm{ml}$ neurons were cultured in the incubator at $37^{\circ} \mathrm{C}, 5 \% \mathrm{CO}_{2}$ and saturated humidity for 6 days; (ii) apoptosis positive (group A); $5 \times 10^{5} / \mathrm{ml}$ neuron suspension was cultured in the incubator at $37^{\circ} \mathrm{C}, 5 \% \mathrm{CO}_{2}$ and saturated humidity for 4 days, neurons were placed into hypoxia culture for $12 \mathrm{~h}$, followed by placement into a $5 \% \mathrm{CO}_{2}$ reoxygenation culture for $24 \mathrm{~h}$; (iii) experimental-I (group $\mathrm{AMPS}_{1}$ ); (iv) experimental-II (group $\mathrm{AMPS}_{2}$ ); (v) experimental-III (group $\mathrm{AMPS}_{3}$ ); and (vi) experimental-IV (group $\mathrm{AMPS}_{4}$ ), following neuronal culturing at $5 \times 10^{5} / \mathrm{ml}$ in the incubator at $37^{\circ} \mathrm{C}, 5 \% \mathrm{CO}_{2}$ and saturated humidity for 4 days, $0.025,0.05,0.10$ or $0.25 \mathrm{~g} / 1$ AMPS was added to the cells for a further $4 \mathrm{~h}$, respectively, the neurons were then placed into hypoxic culture for $12 \mathrm{~h}$ and then placed into $5 \% \mathrm{CO}_{2}$ reoxygenation culture for $24 \mathrm{~h}$.

Hoechst 33342 fluorescence staining. Hoechst 33342 fluorescence staining was performed in accordance with the method used in a previous study (17). Apoptotic neurons were observed by fluorescence microscopy. Neurons (n, 200) were randomly counted under a high power microscope (DMI 3000; Leica Microsystems, Wetzlar, Germany) and the apoptotic rate was calculated. Apoptotic rate $(\%)=$ number of apoptotic neurons/total number of neurons x $100 \%$.

Annexin V/propidium iodide (PI) double staining and flow cytometric detection. The neurons were digested with $0.02 \%$ EDTA and $0.125 \%$ pancreatin solution. The neuronal suspension was centrifuged for $5 \mathrm{~min}(300 \mathrm{x} \mathrm{g})$ and the supernatant was removed. The neurons were rinsed twice with phosphate-buffered saline (PBS) followed by centrifugation for 5 min $(300 \mathrm{x} \mathrm{g})$. Cells $\left(1-5 \times 10^{5}\right)$ were suspended in $500 \mu \mathrm{l}$ binding buffer and $5 \mu 1$ Annexin-FITC was added followed by mixing, $5 \mu \mathrm{l}$ PI was added followed by mixing and cells were incubated at room temperature in the dark for $10 \mathrm{~min}$ followed by centrifugation for $5 \mathrm{~min}(300 \mathrm{x} \mathrm{g})$. The labeling liquid was removed and cells were rinsed with the incubation buffer once. Argon ion exited fluorescence was used for detection by flow cytometry (Coulter Epics XL; Beckman Coulter Inc., Brea, CA, USA). The wavelength was $488 \mathrm{~nm}$.
Flowjo 7.6 software was used (Tree Star Inc., Ashland, OR, USA).

Rhodamine 123 staining and flow cytometric detection. Rhodamine 123 staining was performed according to the manufacturer's instructions. In brief, hypoxia-reoxygenation cultured neurons were digested with $0.02 \%$ EDTA and $0.125 \%$ pancreatin solution, and the mixture was centrifuged for $5 \mathrm{~min}(300 \mathrm{x} \mathrm{g})$. The supernatant was removed, the neurons were rinsed with PBS three times and the Rhodamine 123 dye (final concentration of $0.005 \mathrm{~g} / \mathrm{l}$ ) was added to. Following incubation for $20 \mathrm{~min}$, the neurons were rinsed three times with PBS and incubated for $60 \mathrm{~min}$. Next, the neurons were collected and Argon ion exited fluorescence was used for detection by flow cytometry at a detection wavelength of $488 \mathrm{~nm}$. Flowjo 7.6 software was used to analyze fluorescence intensity.

Quantitative polymerase chain reaction ( $q P C R)$ assay. The qPCR assay (MyCycler ${ }^{\mathrm{TM}}$ Thermal Cycler; Bio-Rad, Hercules, CA, USA) was performed according to the manufacturer's instructions. In brief, mRNA extraction was performed as follows. TRIzol extraction for $5 \mathrm{~min}$, followed by chloroform treatment for $2 \mathrm{~min}$, centrifugation at $12,000 \mathrm{x} \mathrm{g}$ for $15 \mathrm{~min}$, isopropyl alcohol treatment for $20 \mathrm{~min}$, then further centrifugation at $12,000 \mathrm{x} g$ for $10 \mathrm{~min}$. The supernatant was removed and $75 \%$ ethanol precipitation was performed, followed by centrifugation at 7,500 $\mathrm{x}$ g for $5 \mathrm{~min}$, supernatant removal, air drying and the addition of DEPC $\mathrm{H}_{2} \mathrm{O}$ to dissolve mRNA at $65^{\circ} \mathrm{C}$ for $10-15 \mathrm{~min}$. The OD value of the RNA was measured at $260 \mathrm{~nm}$ wavelength using an ultraviolet spectrophotometer. The RNA OD value was used to calculate the concentration as follows: RNA concentration $(\mathrm{mg} / \mathrm{ml})=40 \times \mathrm{OD}_{260}$ value $\mathrm{x}$ dilution ratio/1,000. mRNA reverse transcription to synthesie the cDNA was performed as follows. Total mRNA $(3 \mu \mathrm{l}), 1 \mu \mathrm{l}$ random primer $(0.1 \mu \mathrm{g} / \mathrm{ml}), 10 \mu \mathrm{l} 2 \mathrm{X}$ TS reaction mix, $1 \mu 1$ TransScript $^{\mathrm{TM}}$ RT/RI enzyme mix and $5 \mu 1$ RNasefree water were mixed and incubated at $25^{\circ} \mathrm{C}$ for $10 \mathrm{~min}$, $42^{\circ} \mathrm{C}$ for $30 \mathrm{~min}$ and $85^{\circ} \mathrm{C}$ for $5 \mathrm{~min}$. The $\beta$-actin, Caspase- 3 and $\mathrm{Bax}$ and $\mathrm{Bcl}-2$ genes were amplified according to the following protocol. The cDNA $(3 \mu \mathrm{l}), 1 \mu \mathrm{l}$ forward primer $(10 \mu \mathrm{M}), 1 \mu \mathrm{l}$ reverse primer $(10 \mu \mathrm{M}), 25 \mu \mathrm{l} 2 \mathrm{X}$ TransTap $^{\mathrm{TM}}$

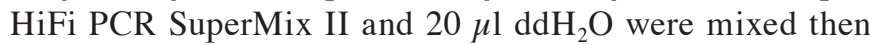
subjected to 32 cycles $\left(94^{\circ} \mathrm{C}\right.$ for $5 \mathrm{~min}, 94^{\circ} \mathrm{C}$ for $30 \mathrm{sec}, 55^{\circ} \mathrm{C}$ for $30 \mathrm{sec}, 72^{\circ} \mathrm{C}$ for $1 \mathrm{~min}$ and $72^{\circ} \mathrm{C}$ for $10 \mathrm{~min}$ ) for $\beta$-actin and Caspase- 3 and 32 cycles $\left(94^{\circ} \mathrm{C}\right.$ for $5 \mathrm{~min}, 94^{\circ} \mathrm{C} 30 \mathrm{sec}$, and $58^{\circ} \mathrm{C}$ for $30 \mathrm{sec}, 72^{\circ} \mathrm{C} 1 \mathrm{~min}$ and $72^{\circ} \mathrm{C}$ for $10 \mathrm{~min}$ ) for Bax and Bcl-2. Agarose electrophoresis was performed using $5 \mu \mathrm{l}$ of the gene samples at $120 \mathrm{~V}$ for $45 \mathrm{~min}$. The OD value of DNA banding was measured by Quantity One. The purpose gene expression quantity was calculated via the ratio of the OD values of the respective gene versus the OD value of the internal control.

The gene primer sequences were: $\beta$-actin forward, 5'-TCAGGTCATCACTATCGGCAAT-3' and reverse, 5'-AAA GAAAGGGTGTAAAACGCA-3', amplification length, 432 bp; Caspase-3 forward, 5'-GCATGCCATATCATCGT CAG-3' and reverse, 5'-GGACCTGTGGACCTGAAAAA-3', amplification length, 159 bp; Bax forward, 5'-GATCAGC TCGGGCACTTTAG-3' and reverse, 5'-TGCAGAGGATGAT 
Table I. Effect of AMPS on the normal cultured cerebral cortical neuronal activity [mean \pm standard deviation (OD Value), $\mathrm{n}=5$ ].

\begin{tabular}{lccc}
\hline Grouping & $\begin{array}{c}\text { Dosage, } \\
\mathrm{g} / \mathrm{l}\end{array}$ & OD Value & $\begin{array}{c}\text { Relative growth } \\
\text { rate }(\%)\end{array}$ \\
\hline $\mathrm{C}$ & 0.00 & $0.269 \pm 0.009$ & 0.00 \\
AMPS & 0.025 & $0.302 \pm 0.012^{\mathrm{a}}$ & 12.34 \\
AMPS & 0.05 & $0.349 \pm 0.018^{\mathrm{a}}$ & 29.84 \\
AMPS & 0.10 & $0.317 \pm 0.006^{\mathrm{a}}$ & 18.05 \\
AMPS & 0.25 & $0.305 \pm 0.013^{\mathrm{a}}$ & 13.59 \\
AMPS & 0.50 & $0.298 \pm 0.009^{\mathrm{a}}$ & 10.98 \\
AMPS & 1.00 & $0.287 \pm 0.006$ & 6.70 \\
AMPS & 2.00 & $0.252 \pm 0.003$ & -6.14 \\
AMPS & 4.00 & $0.241 \pm 0.009$ & -10.48 \\
\hline
\end{tabular}

${ }^{\mathrm{a}} \mathrm{P}<0.05$ vs. group $\mathrm{C}$; relative growth rate $(\%)=$ mean $\mathrm{OD}$ value of the experimental groups - mean OD value of group C / mean OD value of group C x 100\%. AMPS, Atractylodes macrocephalaon polysaccharides; $\mathrm{C}$, normal control group.

TGCTGAC-3', amplification length, $173 \mathrm{bp}$; and Bcl-2 forward, 5'-ATGCCGGTTCAGGTACTCAG-3' and reverse, 5'-CGACT TTGCAGAGATGTCCA-3', amplification length, 223 bp.

Immunocytochemical staining. Neuronal immunocytochemical staining was performed in accordance with the method used in a previous study (17). Rabbit anti-rat neuron-specific enolase polyclonal antibody (diluted 1:50), rabbit anti-rat glial fibrillary acidic protein polyclonal antibody (diluted 1:200), rabbit anti-rat Bcl-2 polyclonal antibody (diluted 1:200), rabbit anti-rat Bax polyclonal antibody (diluted 1:200) or rabbit anti-Caspase-3 polyclonal antibody (diluted 1:400) and goat anti-rabbit IgG secondary antibody were used. Under the light microscope the brown cells were marked as positive cells and the cloudy or unstained cells as negative cells. Cells were randomly counted $(n, 200)$ to calculate the positive rate $(\%)$. Positive rate $=$ number of positive cells/number of total cells $\mathrm{x} 100 \%$.

Statistical analysis. The experimental data are expressed as the mean \pm standard deviation. The comparison among groups was performed using one-way analysis of variance and least significant difference tests were used for comparison between two groups. $\mathrm{P}<0.05$ was considered to indicate a statistically significant difference.

\section{Results}

Effect of AMPS on the cultured cerebral cortical neurons. Following four days of culturing, the neurons were incubated with AMPS for $48 \mathrm{~h}$. The MTT assay showed that the neuronal activity improved following treatment with $0.025-1.0 \mathrm{~g} / 1$ AMPS, but a significant increase was only observed at 0.025-0.50 g/l treatment as compared with those in group $\mathrm{C}$ $(\mathrm{P}<0.05)$. Cytotoxicity was observed when the dosage was increased to $2.0 \mathrm{~g} / \mathrm{l}$ (Table I).
Effect of AMPS on the cultured cerebral cortical neurons induced by hypoxia/reoxygenation. Following 4 days of culturing, AMPS was added for a $4 \mathrm{~h}$ pretreatment, followed by $12 \mathrm{~h}$ hypoxia and $24 \mathrm{~h}$ reoxygenation culture. The neuronal activity improved following treatment with 0.025-0.5 g/l AMPS and was significantly increased in the 0.025-0.05 g/l group as compared with that in group $\mathrm{A}(\mathrm{P}<0.05)$, although the neuronal activity remained decreased as compared with that in group $\mathrm{C}(\mathrm{P}<0.05)$. Cytotoxicity was observed when the dosage was increased to $1.0 \mathrm{~g} / 1$ (Table II). These results suggest that the hypoxic neurons may be protected by $0.025-0.5 \mathrm{~g} / \mathrm{l}$ AMPS.

Effect of AMPS on cerebral cortical neuronal apoptosis induced by hypoxia/reoxygenation. Following 4 days of culturing, AMPS was added for $4 \mathrm{~h}$ pretreatment, followed by $12 \mathrm{~h}$ hypoxia and $24 \mathrm{~h}$ reoxygenation culture. The neuronal apoptosis rate following treatment with $0.025-0.25 \mathrm{~g} / \mathrm{l}$ AMPS was significantly decreased, particularly at $0.025 \mathrm{~g} / \mathrm{l}$, as indicated by the Hoechst-33342 fluorescence staining, as compared with that in group $\mathrm{A}(\mathrm{P}<0.05)$, although the neuronal apoptosis rate remained increased as compared with that in group $\mathrm{C}$ $(\mathrm{P}<0.05$; Table III).

Following 4 days of culturing, AMPS was added for $4 \mathrm{~h}$ pretreatment, followed by $12 \mathrm{~h}$ hypoxia and $24 \mathrm{~h}$ reoxygenation culture. The neuronal apoptosis rates following treatment with AMPS at 0.025-0.25 g/l were significantly decreased in early apoptosis, particularly at $0.025 \mathrm{~g} / 1$, as observed by Annexin V/PI double staining, as compared with those in group $\mathrm{A}(\mathrm{P}<0.05)$. However, the neuronal apoptotic rates remained increased as compared with those in group $\mathrm{C}(\mathrm{P}<0.05)$. In the late apoptosis rate there were no marked differences in each AMPS group as compared with that in group A ( $\mathrm{P}>0.05$; Table IV).

Following 4 days of culturing, AMPS was added for $4 \mathrm{~h}$ pretreatment, followed by $12 \mathrm{~h}$ hypoxia and $24 \mathrm{~h}$ reoxygenation culture. Rhodamine 123 mean fluorescence intensity and the mitochondrial injury of neurons following treatment with 0.025-0.10 g/l AMPS were significantly increased and alleviated, particularly at $0.05 \mathrm{~g} / 1$, as compared with those in group A $(\mathrm{P}<0.05)$. However, Rhodamine 123 mean fluorescence intensity was decreased as compared with that in group $\mathrm{C}(\mathrm{P}<0.05$; Table $\mathrm{V}$; Fig. 1). The results suggest that hypoxic neuronal apoptosis was significantly decreased following AMPS administration.

Following 4 days of culturing, AMPS was added for $4 \mathrm{~h}$ pretreatment, followed by $12 \mathrm{~h}$ hypoxia and $24 \mathrm{~h}$ reoxygenation culture. mRNA expression of Caspase-3 in neurons treated with 0.025-0.05 g/1 AMPS was significantly downregulated and the Bax mRNA expression of neurons treated with $0.05 \mathrm{~g} / 1$ AMPS was significantly downregulated as indicated by PCR as compared with that in group $\mathrm{A}(\mathrm{P}<0.05)$. However, the mRNA expression of Caspase- 3 and Bax of neurons remained increased. The mRNA expression of Bcl- 2 in neurons remained decreased as compared with that in group $\mathrm{C}(\mathrm{P}<0.05$; Table VI; Fig. 2). The results suggested that the hypoxic neuronal apoptosis reduction was due to a decreased expression of apoptosis regulating genes following AMPS administration.

Following 4 days of culturing, AMPS was added for $4 \mathrm{~h}$ pretreatment, followed by $12 \mathrm{~h}$ hypoxia and $24 \mathrm{~h}$ reoxygenation culture. The expression of Caspase- 3 protein of neurons treated with 0.025-0.25 g/l AMPS was significantly downregulated, 
Table II. Effect of AMPS on the hypoxia/reoxygenation cultured cerebral cortical neuronal activity [mean \pm standard deviation (OD Value), $n=5]$.

\begin{tabular}{lcccc}
\hline Grouping & Dosage, g/l & OD value & Relative growth rate 1, \% & Relative growth rate 2, \% \\
\hline C & 0 & $0.593 \pm 0.057$ & 215.59 & 100.00 \\
A & 0 & $0.275 \pm 0.045^{\mathrm{a}}$ & 100.00 & 46.39 \\
AMPS & 0.025 & $0.392 \pm 0.036^{\mathrm{ab}}$ & 142.69 & 66.19 \\
AMPS & 0.05 & $0.397 \pm 0.035^{\mathrm{ab}}$ & 144.22 & 66.90 \\
AMPS & 0.10 & $0.366 \pm 0.016^{\mathrm{a}}$ & 132.95 & 61.67 \\
AMPS & 0.25 & $0.346 \pm 0.027^{\mathrm{a}}$ & 125.75 & 58.33 \\
AMPS & 0.50 & $0.301 \pm 0.025^{\mathrm{a}}$ & 109.53 & 50.80 \\
AMPS & 1.00 & $0.257 \pm 0.016^{\mathrm{a}}$ & 93.33 & 43.29 \\
\hline
\end{tabular}

${ }^{\text {ap }}<0.05$ vs. group $\mathrm{C}$; ${ }^{\mathrm{b}} \mathrm{P}<0.05$ vs. group $\mathrm{A}$; relative growth rate $1(\%)=$ mean $\mathrm{OD}$ value of the experimental groups / mean OD value of group $\mathrm{A}$ $\mathrm{x} 100 \%$; Relative growth rate $2(\%)=$ mean OD value of the experimental group / mean OD value of group C x $100 \%$. C, normal control group; A; apoptosis control group; AMPS, Atractylodes macrocephalaon polysaccharides.

Table III. Effect of AMPS against neuronal apoptosis induced by hypoxia/reoxygenation by the Hoechst 33342 fluorescence staining detection [mean \pm standard deviation $(\%), \mathrm{n}=3$ ]

\begin{tabular}{lcc}
\hline Grouping & Dosage, $\mathrm{g} / \mathrm{l}$ & Apoptosis rate, $\%$ \\
\hline $\mathrm{C}$ & 0 & $6.48 \pm 0.55$ \\
$\mathrm{~A}$ & 0 & $37.61 \pm 2.87^{\mathrm{a}}$ \\
$\mathrm{AMPS}_{1}$ & 0.025 & $22.89 \pm 0.78^{\mathrm{ab}}$ \\
$\mathrm{AMPS}_{2}$ & 0.05 & $24.20 \pm 1.04^{\mathrm{ab}}$ \\
$\mathrm{AMPS}_{3}$ & 0.1 & $28.33 \pm 1.52^{\mathrm{abc}}$ \\
$\mathrm{AMPS}_{4}$ & 0.25 & $31.28 \pm 1.84^{\mathrm{abcd}}$ \\
\hline
\end{tabular}

${ }^{\text {ap }}<0.05$ vs. group $\mathrm{C}$; ${ }^{\mathrm{b}} \mathrm{P}<0.05$ vs. group $\mathrm{A}$; ${ }^{\mathrm{c}} \mathrm{P}<0.05$ vs. the $\mathrm{AMPS}_{1}$ group; ${ }^{\mathrm{d}} \mathrm{P}<0.05$ vs. the $\mathrm{AMPS}_{2}$ group. AMPS, Atractylodes macrocephalaon polysaccharides; C, normal control group; A; apoptosis control group.

Table IV. Effect of AMPS against neuronal apoptosis induced by hypoxia/reoxygenation by Annexin V/PI double staining and the flow cytometer detection [mean \pm standard deviation $(\%), \mathrm{n}=3]$.

\begin{tabular}{lccc}
\hline Grouping & $\begin{array}{c}\text { Dosage, } \\
\mathrm{g} / \mathrm{l}\end{array}$ & $\begin{array}{c}\text { Early apoptosis } \\
\text { rate, } \%\end{array}$ & $\begin{array}{c}\text { Late apoptosis } \\
\text { rate, } \%\end{array}$ \\
\hline $\mathrm{C}$ & 0 & $2.46 \pm 0.58$ & $0.52 \pm 0.34$ \\
$\mathrm{~A}$ & 0 & $51.50 \pm 2.44^{\mathrm{a}}$ & $9.63 \pm 6.03^{\mathrm{a}}$ \\
$\mathrm{AMPS}_{1}$ & 0.025 & $21.47 \pm 0.67^{\mathrm{ab}}$ & $11.93 \pm 3.80^{\mathrm{a}}$ \\
$\mathrm{AMPS}_{2}$ & 0.05 & $28.83 \pm 2.32^{\mathrm{abc}}$ & $5.78 \pm 2.74 \%$ \\
$\mathrm{AMPS}_{3}$ & 0.1 & $37.67 \pm 3.31^{\mathrm{abcd}}$ & $4.85 \pm 1.29^{\mathrm{c}}$ \\
$\mathrm{AMPS}_{4}$ & 0.25 & $44.80 \pm 1.41^{\mathrm{abcde}}$ & $8.25 \pm 2.30^{\mathrm{a}}$ \\
\hline
\end{tabular}

${ }^{\mathrm{a}} \mathrm{P}<0.05$ vs. group $\mathrm{C}$; ${ }^{\mathrm{b}} \mathrm{P}<0.05$ vs. group $\mathrm{A}$; ${ }^{\mathrm{C}} \mathrm{P}<0.05$ vs. the $\mathrm{AMPS}_{1}$ group; ${ }^{\mathrm{d}} \mathrm{P}<0.05$ vs the $\mathrm{AMPS}_{2}$ group; ${ }^{\mathrm{e}} \mathrm{P}<0.05$ vs. the $\mathrm{AMPS}_{3}$ group. AMPS, Atractylodes macrocephalaon polysaccharides; C, normal control group; A; apoptosis control group.
Table V. Effect of AMPS against mitochondrial injury of neurons induced by hypoxia/reoxygenation by Rhodamine 123 staining and flow cytometer detection [mean \pm standard deviation (MFI), $\mathrm{n}=3$ ].

\begin{tabular}{lcc}
\hline Grouping & Dosage, g/l & MFI \\
\hline C & 0 & $232.33 \pm 17.62$ \\
A & 0 & $34.30 \pm 13.00^{\mathrm{a}}$ \\
$\mathrm{AMPS}_{1}$ & 0.025 & $178.00 \pm 12.29^{\mathrm{ab}}$ \\
$\mathrm{AMPS}_{2}$ & 0.05 & $204.00 \pm 8.00^{\mathrm{abc}}$ \\
$\mathrm{AMPS}_{3}$ & 0.1 & $128.67 \pm 16.62^{\mathrm{abcd}}$ \\
$\mathrm{AMPS}_{4}$ & 0.25 & $41.17 \pm 41.17^{\mathrm{acde}}$ \\
\hline
\end{tabular}

${ }^{\mathrm{a}} \mathrm{P}<0.05$ vs. group $\mathrm{C}$; ${ }^{\mathrm{b}} \mathrm{P}<0.05$ vs. group $\mathrm{A} ;{ }^{\mathrm{c}} \mathrm{P}<0.05$ vs. the $\mathrm{AMPS}_{1}$ group; ${ }^{\mathrm{d}} \mathrm{P}<0.05$ vs. the $\mathrm{AMPS}_{2}$ group ; ${ }^{\mathrm{e}}<0.05$ vs. the $\mathrm{AMPS}_{3}$ group. MFI, mean fluorescence intensity; AMPS, Atractylodes macrocephalaon polysaccharides; $\mathrm{C}$, normal control group; $\mathrm{A}$; apoptosis control group.

particularly at $0.05 \mathrm{~g} / 1$, the expression of Bax protein of neurons treated with 0.025-0.25 g/l AMPS was significantly downregulated, particularly at $0.05 \mathrm{~g} / \mathrm{l}$ and the expression of $\mathrm{Bcl}-2$ protein of neurons treated with 0.025-0.25 g/l AMPS was significantly upregulated, particularly at $0.05 \mathrm{~g} / \mathrm{l}$ treatment, as indicated by immunocytochemical staining as compared with those in group A $(\mathrm{P}<0.05)$. However, the expression of Caspase- 3 and Bax proteins in neurons remained increased and the expression of Bcl-2 protein of neurons remained decreased as compared with those in group $\mathrm{C}(\mathrm{P}<0.05$; Table VII). The results suggested that the reduction of neuronal apoptosis under hypoxia following AMPS treatment was due to a decrease in the expression of apoptosis-initiating proteins and an increase in anti-apoptotic proteins.

Following 4 days of culturing, AMPS was added for $4 \mathrm{~h}$ pretreatment, followed by $12 \mathrm{~h}$ hypoxia and $24 \mathrm{~h}$ reoxygenation culture. The ratio of Bcl-2/Bax was significantly increased by AMPS at 0.025-0.05 g/l for genes and at 0.025-0.10 g/l for 


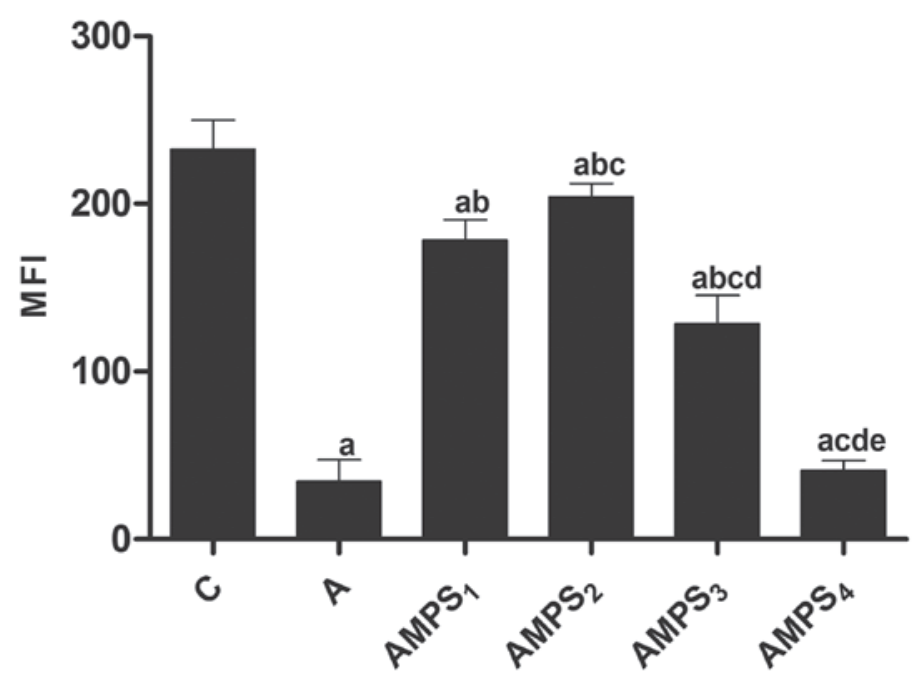

Figure 1. MFI of in vitro cultured cerebral cortical neurons stained with Rhodamine 123 fluorescence by flow cytometer detection. (C) Normal control group; (A) apoptosis positive group; $\mathrm{AMPS}_{1}(0.025 \mathrm{~g} / \mathrm{l}) ; \mathrm{AMPS}_{2}(0.05 \mathrm{~g} / \mathrm{l}) ; \mathrm{AMPS}_{3}(0.10 \mathrm{~g} / \mathrm{l}) ;$ and $\mathrm{AMPS}_{4}(0.25 \mathrm{~g} / \mathrm{l}) .{ }^{\mathrm{a}} \mathrm{P}<0.05$ vs. group C; ${ }^{\text {b }} \mathrm{P}<0.05 \mathrm{vs}$. group A; ${ }^{\mathrm{C}} \mathrm{P}<0.05$ vs. the AMPS1 group; ${ }^{\mathrm{d}} \mathrm{P}<0.05$ vs. the AMPS2 group ; ${ }^{\mathrm{e}} \mathrm{P}<0.05$ vs. the AMPS3 group; AMPS, Atractylodes macrocephalaon polysaccharides; MFI, mean fluorescence intensity.

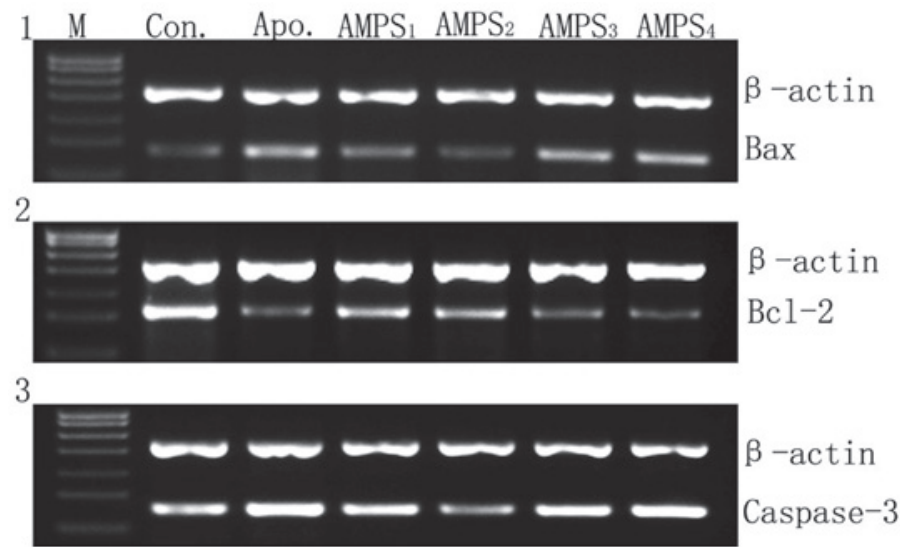

Figure 2. mRNA expression of Bax, Bcl-2 and Caspase-3 of in vitro cultured cerebral cortical neurons by polymerase chain reaction assay. The first row ' $\mathrm{M}$ ' represents the marker; rows 2-7 represent groups C, A, AMPS $1, \mathrm{AMPS}_{2}, \mathrm{AMPS}_{3}$ and $\mathrm{AMPS}_{4}$, respectively. AMPS, Atractylodes macrocephalaon polysaccharides.

proteins in neurons exposed to hypoxia-reoxygenation as compared with that in group A $(\mathrm{P}<0.05)$. However, the ratio of $\mathrm{Bcl}-2 / \mathrm{Bax}$ remained decreased as compared with that in group $\mathrm{C}(\mathrm{P}<0.05$; Table VI-VII). The results suggested that the reduction in hypoxic neuronal apoptosis was due to a significantly elevated ratio of $\mathrm{Bcl}-2 / \mathrm{Bax}$ at the gene and protein levels following AMPS administration.

\section{Discussion}

Rhizoma Atractylodis macrocephalae, which has similarities with ginseng, Astragalus and Polygonatum, is a qi-invigorating herb in TCM and has been used for thousands of years in the treatment of cerebrovascular disease and neurological disorders in China. Preparations containing the major components of rhizoma Atractylodis macrocephalae (1) have a marked therapeutic benefit against ischemic stroke. A decoction of Palmul-Chongmyeong-Tang with the major pharmaceutically active components of rhizoma Atractylodis macrocephalae was administered to rats with $\mathrm{MCAO}$ and produced a significant improvement in escape latency to find the platform in the Morris water maze and reduced the loss of cholinergic immunoreactivity in the hippocampus induced by cerebral ischemia (20). A preparation containing the major components of rhizoma Atractylodis macrocephalae was administered to mice injured by repetitive cerebral ischemia-reperfusion in a model of VD and inhibited lipid peroxidation (LPO), elevated activity in $\left(\mathrm{Na}^{+}\right)-\left(\mathrm{K}^{+}\right)$-ATPase and $\left(\mathrm{Ca}^{2+}\right)$-ATPase and reduced the production of nitric oxide (NO) in cortical tissue (21). AMPS are the active ingredients of the Chinese Herbal Medicine rhizoma Atractylodis macrocephalae. In rat models of MCAO, the neurological deficit scores and injured neurons in the AMPS group were significantly lower and fewer compared with the MCAO group following femoral vein injection with $4 \%$ AMPS solution $(40 \mathrm{mg} / \mathrm{kg}$ b.w.) $(\mathrm{P}<0.05-0.01)$. In addition, AMPS markedly inhibited iNOS expression and alleviated brain edema in ischemic areas $(6,7)$. D-galactose-induced 
Table VI. Effect of AMPS on mRNA expression of Caspase-3, Bax and Bcl-2 in neurons induced by hypoxia/reoxygenation by polymerase chain reaction assay [mean \pm standard deviation (OD value), $n=3$ ].

\begin{tabular}{|c|c|c|c|c|c|}
\hline Grouping & Dosage $(\mathrm{g} / \mathrm{l})$ & Caspase-3 & Bax & $\mathrm{Bcl}-2$ & $\mathrm{Bcl}-2 / \mathrm{Bax}$ \\
\hline $\mathrm{C}$ & 0 & $0.62 \pm 0.03$ & $0.32 \pm 0.01$ & $0.81 \pm 0.15$ & $2.56 \pm 0.51$ \\
\hline A & 0 & $1.02 \pm 0.03^{\mathrm{a}}$ & $0.70 \pm 0.02^{\mathrm{a}}$ & $0.48 \pm 0.04^{\mathrm{a}}$ & $0.68 \pm 0.04^{\mathrm{a}}$ \\
\hline AMPS $_{1}$ & 0.025 & $0.82 \pm 0.04^{\mathrm{ab}}$ & $0.44 \pm 0.07$ & $0.68 \pm 0.09$ & $1.55 \pm 0.12^{\mathrm{b}}$ \\
\hline $\mathrm{AMPS}_{2}$ & 0.05 & $0.54 \pm 0.05^{\mathrm{bc}}$ & $0.33 \pm 0.06^{\mathrm{b}}$ & $0.66 \pm 0.11$ & $2.02 \pm 0.02^{\mathrm{abc}}$ \\
\hline $\mathrm{AMPS}_{3}$ & 0.1 & $0.94 \pm 0.03^{\mathrm{ad}}$ & $0.65 \pm 0.10$ & $0.58 \pm 0.14$ & $0.93 \pm 0.33^{\text {acd }}$ \\
\hline $\mathrm{AMPS}_{4}$ & 0.25 & $1.14 \pm 0.09^{\mathrm{ad}}$ & $0.42 \pm 0.37$ & $0.28 \pm 0.24^{\mathrm{a}}$ & $0.69 \pm 0.10^{\mathrm{ac}}$ \\
\hline
\end{tabular}

${ }^{\mathrm{a}} \mathrm{P}<0.05$ vs. group $\mathrm{C} ;{ }^{\mathrm{b}} \mathrm{P}<0.05$ vs. group $\mathrm{A} ;{ }^{\mathrm{c}} \mathrm{P}<0.05$ vs. the AMPS1 group; ${ }^{\mathrm{d}} \mathrm{P}<0.05$ vs. the AMPS 2 group. AMPS, Atractylodes macrocephalaon polysaccharides; C, normal control group; A; apoptosis control group; Bcl-2, B-cell lymphoma 2; Bax, Bcl-2-associated X protein.

Table VII. Effect of AMPS on protein expression of Caspase-3, Bax and Bcl-2 in neurons induced by hypoxia/reoxygenation by immunocytochemical staining [mean \pm standard deviation $(\%), \mathrm{n}=3$ ]

\begin{tabular}{lccccc}
\hline Grouping & Dosage $(\mathrm{g} / \mathrm{l})$ & Caspase-3 & Bax & Bcl-2 & Bcl-2/Bax \\
\hline $\mathrm{C}$ & 0 & $37.03 \pm 0.38$ & $53.32 \pm 0.77$ & $59.36 \pm 2.23$ & $1.11 \pm 0.03$ \\
$\mathrm{~A}$ & 0 & $58.89 \pm 0.45^{\mathrm{a}}$ & $65.08 \pm 1.02^{\mathrm{a}}$ & $37.83 \pm 1.08^{\mathrm{a}}$ & $0.58 \pm 0.01^{\mathrm{a}}$ \\
$\mathrm{AMPS}_{1}$ & 0.025 & $49.51 \pm 1.60^{\mathrm{ab}}$ & $54.11 \pm 0.72^{\mathrm{b}}$ & $52.68 \pm 1.51^{\mathrm{ab}}$ & $0.97 \pm 0.04^{\mathrm{b}}$ \\
$\mathrm{AMPS}_{2}$ & 0.05 & $46.61 \pm 0.73^{\mathrm{ab}}$ & $52.69 \pm 1.04^{\mathrm{b}}$ & $54.54 \pm 0.41^{\mathrm{ab}}$ & $1.03 \pm 0.02^{\mathrm{b}}$ \\
$\mathrm{AMPS}_{3}$ & 0.1 & $54.44 \pm 1.16^{\mathrm{abcd}}$ & $57.00 \pm 0.75^{\mathrm{abcd}}$ & $46.73 \pm 0.81^{\mathrm{abcd}}$ & $0.82 \pm 0.02^{\mathrm{abd}}$ \\
$\mathrm{AMPS}_{4}$ & 0.25 & $56.72 \pm 0.28^{\mathrm{abcde}}$ & $60.15 \pm 2.34^{\mathrm{abcde}}$ & $43.98 \pm 1.76^{\mathrm{abcde}}$ & $0.73 \pm 0.05^{\mathrm{acd}}$ \\
\hline
\end{tabular}

${ }^{\mathrm{a}} \mathrm{P}<0.05$ vs. group $\mathrm{C}$; ${ }^{\mathrm{b}} \mathrm{P}<0.05$ vs group $\mathrm{A} ;{ }^{\mathrm{c}} \mathrm{P}<0.05$ vs. the $\mathrm{AMPS}_{1}$ group; ${ }^{\mathrm{d}} \mathrm{P}<0.05$ vs. the $\mathrm{AMPS}_{2}$ group $;{ }^{\mathrm{e}} \mathrm{P}<0.05$ vs the $\mathrm{AMPS}$ group. AMPS, Atractylodes macrocephalaon polysaccharides; C, normal control group; A; apoptosis control group; Bcl-2, B-cell lymphoma 2; Bax, Bcl-2associated X protein.

mimetic aging mice treated by intragastric administration of AMPS $(0.28 \mathrm{~g} / \mathrm{kg}$ b.w/d) significantly elevated the levels of SOD and glutathione peroxidase (GSH-Px) and decreased MDA and DNA damage in the cerebral cortex neurons of rats (8). Following intragastric administration of a rhizoma Atractylodis macrocephalae decoction or AMPS to mice, the learning ability, memory and SOD activity in the brain was significantly increased, while the contents of MDA and lipofuscin (LPF) in the brain were markedly decreased (9). When AMPS was administered to aged rats, the Caspase- 3 activity ratio, expression levels of the second mitochondria-derived activator of caspases (Smac/DIABLO), which is a secondary mitochondria-derived activator of Caspases and HtrA2/Omi protein, a mitochondrial serine protease, as well as levels of Smac/DIABLO and HtrA2/Omi mRNA levels were markedly reduced and cell apoptosis was inhibited in the aged rats (22).

According to TCM, Herbal Medicines with the same properties exert identical or similar therapeutic effects. It has been confirmed that qi-invigorating herbs and their active ingredients are efficacious against neuronal apoptosis. In vitro, ginseng pectin attenuates $\mathrm{H}_{2} \mathrm{O}_{2}$-induced cell damage at $>26 \%$ and increases the phosphorylation of the extracellular signal-regulated kinases 1 and 2 and Akt in primary cortical neuronal cells, which suggests that ginseng possesses a neuroprotective effect against $\mathrm{H}_{2} \mathrm{O}_{2}$-induced neuronal apoptosis (23). The aqueous extract of ginseng exerts an inhibitory effect on cell death, overproduction of ROS and release of cyt $C$ in 1-methyl-4-phenylpyridinium ion-induced cytotoxicity of SH-SY5Y cells (24). Ginsenosides Rb1 and $\mathrm{Rg} 1$ protected spinal neurons from excitotoxicity induced by glutamate and kainic acid, as well as oxidative stress induced by $\mathrm{H}_{2} \mathrm{O}_{2}$. These neuroprotective effects are dose-dependent (25). A rhizoma Atractylodis macrocephalae extract significantly increased cell viability and reduced neuronal apoptosis in glutamate excitotoxicity-induced neuronal apoptosis of primary cultured cerebral cortical neurons (15). Neuronal hypoxia led to the generation of free oxygen radicals, ROS, which injures mitochondria and induces cell apoptosis. However, Rhodamine 123 mean fluorescence intensity was significantly increased and the mitochondrial injury of neurons was significantly alleviated in the hypoxic neurons pre-treated with AMPS, which suggests that AMPS is a potent scavenger of ROS. Notably, it was demonstrated by Hoechst 33342 and Annexin V/PI double fluorescence staining that the apoptosis of hypoxic neurons was significantly inhibited by AMPS administration; however, this was pharmacologically dose-dependent.

Whether cell apoptosis occurs depends on the expression of pro- or anti-apoptotic genes and their protein production, particularly the ratio of $\mathrm{Bcl}-2 / \mathrm{Bax}$. Caspase- 3 and Bax are pro-apoptotic, whereas $\mathrm{Bcl}-2$ has anti-apoptotic properties. 
In a rat model of $\mathrm{MCAO}$, ginsenosides $\mathrm{Rg} 2$ and $\mathrm{Rg} 3$ showed significant neuroprotective effects and improved the neurological responses and memory ability, which significantly suppressed the expression of Caspase-3 mRNA, as well as Bax and P53 proteins, increased the expression of Bcl-2 and Hsp70 proteins and markedly reduced cerebral infarct volumes $(10,13)$. In a mouse model of BCCAO, an Astragalus extract significantly downregulated the expression of Caspase- 9 and Caspase-3, increased neurocyte survival and decreased the neurocyte apoptosis rate (11). In a rat model of MCAO, astragaloside IV downregulated Caspase-3 mRNA expression and upregulated Bcl-2 expression (12). In a rat model of neonatal hypoxia-ischemia, the neuronal death rate and Caspase-3 mRNA levels were significantly reduced in the hippocampal CA1 area and the discrimination learning ability of developed rats were markedly improved in the Astragulus-membraneaceus-treated group as compared with those in the model group (26).

In vitro, the neuroprotective effect of ginsenoside Rg1 was due to a decrease in the expression of Caspase- 3 and an increase in the ratio of $\mathrm{Bcl}-2 / \mathrm{Bax}$ at the protein level in primary cultured rat hippocampal neuronal cells treated with A $\beta$ (25-35 amino acids) (16). Previous studies by our group have also demonstrated that ginsenoside Rb1 (27), Panax quinquefolium L. saponin (28), Astragalus injection (29), Polygonatum polysaccharide (17) and white hyacinth bean polysaccharide (18) exhibited activity against apoptosis of rat cerebral cortical neurons induced by hypoxia-reoxygenation primary culture, and their neuroprotective effects against the apoptosis of neurons significantly reduced the levels of Bax and Caspase- 3 protein and mRNA expression, increased the levels of Bcl-2 protein and mRNA expression and elevated the ratio of $\mathrm{Bcl}-2 / \mathrm{Bax}$. In the present study, AMPS significantly prevented apoptosis of cerebral cortical neurons exposed to hypoxia. Furthermore, AMPS significantly downregulated the levels of Caspase- 3 and Bax mRNA expression between 0.025 and $0.05 \mathrm{~g} / \mathrm{l}$ and the levels of Caspase- 3 and Bax protein expression between 0.025 and $0.25 \mathrm{~g} / \mathrm{l}$. AMPS caused a significant upregulation of the levels of Bcl-2 protein expression between 0.025 and $0.25 \mathrm{~g} / 1$ and the ratio of $\mathrm{Bcl}-2 / \mathrm{Bax}$ between 0.025 and $0.05 \mathrm{~g} / 1$ for mRNA expression and between 0.025 and $0.10 \mathrm{~g} / 1$ for protein expression.

In TCM, polysaccharides contained in Chinese Medicinal Herbs with qi-invigorating properties are applied to improve immune function for treating diseases. However, it has been found that polysaccharides from Chinese Medicinal Herbs with qi-invigorating properties exert antioxidative, anti-apoptotic and anti-aging effects. Since ginseng, Astragalus and Polygonatum have been applied to treat ischemic cerebral and neurodegenerative diseases and anti-aging in TCM and rhizoma Atractylodis macrocephalae is, as ginseng, Astragalus and Polygonatum, a qi-invigorating herb in TCM and AMPS is an active ingredient of rhizoma Atractylodis macrocephalae, AMPS may be applied to prevent and treat ischemic cerebral and neurodegenerative diseases and anti-aging in a single herb or combined preparation. AMPS may be administered orally and intravenously. The neuroprotective effect of AMPS against neuronal apoptosis induced by hypoxia may be due to their capability to significantly decrease the levels of Bax and Caspase- 3 genes and protein expression, and increase the levels of $\mathrm{Bcl}-2$ protein expression, thus elevating the ratio of $\mathrm{Bcl}-2 / \mathrm{Bax}$ in hypoxic neurons. These data provide a theoretical basis and hypothesis for the reasonable administration of AMPS in preventing and treating ischemic cerebral diseases and aging effects.

\section{Acknowledgements}

This study was supported by The 'Social Development Key Research Project' of Jiangxi Provincial Department of Science and Technology (no. 2007BS22602).

\section{References}

1. Li P, Li HY and Yuan YZ: Pinellia rhizoma atractylodis macrocephalae gastrodia elata tang add and subtract joint vinpocetine treating patients with acute cerebral infarction. J Medical Forum 33: 123-124, 2012 (In Chinese).

2. Chen W, Huang HL, Sun YX, Xu XJ and Zhou D: Observation of curative effect on pinellia rhizoma atractylodis macrocephalae gastrodia elata tang add and subtract treating 128 patients with vertebral basilar artery insufficiency vertigo. J Guangdong Med College 30: 173-174, 2012 (In Chinese).

3. Zhang GM, Sun SL and Gao Y: Clinical study on treatment of acute ischemic stroke by therapy of strengthening the genuine and protecting brain. J Beijing Univer of TCM (Clin Med) 10: 7-10, 2003 (In Chinese).

4. Chen WP, Ma L, Toshihide $\mathrm{H}$ and Wang QW: Treatment of vascular dementia by Naozhitong Capsule: a clinical observation of 18 cases. J New Chin Med 36: 16-18, 2004 (In Chinese).

5. Li SC, Fan JF, Li SP, Chai Y, Kong SZ and Yu XM: Observation on curative effects of supplemented Rhizoma Polygonati Sicao decoction on the patients with ischemic brain damage. Zhongguo Zhongxiyi Jiehe Jijiu Zazhi 8: 376-377, 2001 (In Chinese).

6. Wang GW, Feng Y, Liu YL, Li JX and Qiu XM: Neuroprotective effect of polysaccharide of Atractylodes macrocephala Koidz on focal cerebral ischemia reperfusion in rats. Food Sci 30: 220-222, 2009 (In Chinese).

7. Wang GW, Feng Y, Liu YL and Qiu XM: Effect of Polysaccharide from Atractylodes macrocephala Koidz on inducible nitric oxide synthase after focal cerebral ischemia reperfusion in rats. Food Sci 30: 273-275, 2009 (In Chinese).

8. Ma QH, Zhang PX, Guo HY, Wei XD and Ou Q: Effect of Rhizoma Atractylodis macrocephalae polysaccharide on neural cell antioxidation in the D - galactose induced rat aging. Chin J Geront 26: 1658-1660, 2006 (In Chinese).

9. Xu LS, Jin XL and Shao LX: The effect of Atractylodes macrocephala and Polysaccharide of Atractylodes macrocephala on learning and memory and anti-oxidation of mice. Bull Sci Tech 9: 513-515, 2003 (In Chinese).

10. He B, Chen P, Yang J, Yun Y, Zhang X, Yang R and Shen, Z: Neuroprotective effect of 20(R)-ginsenoside $\operatorname{Rg}(3)$ against transient focal cerebral ischemia in rats. Neurosci Lett 526: 106-111, 2012.

11. Huang XP, Tan H, Chen BY and Deng CQ: Astragalus extract alleviates nerve injury after cerebral ischemia by improving energy metabolism and inhibiting apoptosis. Biol Pharm Bull 35: 449-454, 2012

12. Yang J, Li J, Lu J, Zhang Y, Zhu Z and Wan H: Synergistic protective effect of astragaloside IV-tetramethylpyrazine against cerebral ischemic-reperfusion injury induced by transient focal ischemia. J Ethnopharmacol 140: 64-72, 2012.

13. Zhang G, Liu A, Zhou Y, San X, Jin T and Jin Y: Panax ginseng ginsenoside-Rg2 protects memory impairment via anti-apoptosis in a rat model with vascular dementia. J Ethnopharmacol 115: 441-448, 2008

14. Li WZ, Li WP, Zhang W, et al: Protective effect of extract of Astragalus on learning and memory impairments and neurons' apoptosis induced by glucocorticoids in 12-month-old male mice. Anat Rec (Hoboken) 294: 1003-1014, 2011.

15. Gao Q, Ji ZH, Yang Y, Cheng R and Yu XY: Neuroprotective effect of Rhizoma Atractylodis macrocephalae against excitotoxicity-induced apoptosis in cultured cerebral cortical neurons. Phytother Res 26: 557-561, 2012. 
16. Gong L, Li SL, Li H and Zhang L: Ginsenoside Rg1 protects primary cultured rat hippocampal neurons from cell apoptosis induced by $\beta$-amyloid protein. Pharm Biol 49: 501-507, 2011.

17. Hu GZ, Zhang J, Tang N, Wen Z and Nie RQ: Effect of polygonatum polysaccharide on the hypoxia-induced apoptosis and necrosis in in vitro cultured cerebral cortical neurons from neonatal rats. Nerve Regen Res 1: 26-31, 2006.

18. Hu GZ, Yao YF, Wen Z and Gao YQ: Protective effect of white hyacinth bean polysaccharide on the apoptosis of fetal rat cerebral cortical neurons induced by hypoxia. Pharma Clin Chin Mat Med 28: 91-94, 2012 (In Chinese).

19. Yao YF, Hu GZ, Gao YQ and Wen Z: The effect of white hyacinth bean polysaccharide on the anti-apoptosis and necrosis of fetal rat cerebral cortical neurons induced by hypoxia. Pharma Clin Chin Mat Med 28: 58-62, 2012 (In Chinese).

20. Yun YJ, Lee B, Hahm DH, et al: Neuroprotective effect of palmul-chongmyeong-tang on ischemia-induced learning and memory deficits in the rat. Biol Pharm Bull 30: 337-342, 2007.

21. Lin Z, Yan Y, Zhu D, Yu B and Wang Q: Protective effects of FBD - an experimental Chinese traditional medicinal formula on memory dysfunction in mice induced by cerebral ischemia-reperfusion. J Ethnopharmacol 97: 477-483, 2005.

22. Guo L, Sun YL, Wang AH, Xu CE and Zhang MY: Effect of polysaccharides extract of rhizoma atractylodis macrocephalae on thymus, spleen and cardiac indexes, caspase-3 activity ratio, Smac/DIABLO and HtrA2/Omi protein and mRNA expression levels in aged rats. Mol Biol Rep 39: 9285-9290, 2012.
23. Fan Y, Sun C, Gao X, et al: Neuroprotective effects of ginseng pectin through the activation of ERK/MAPK and Akt survival signaling pathways. Mol Med Rep 5: 1185-1190, 2012

24. Hu S, Han R, Mak S and Han Y: Protection against 1-methyl-4-phenylpyridinium ion $\left(\mathrm{MPP}^{+}\right)$-induced apoptosis by water extract of ginseng (Panax ginseng C.A. Meyer) in SH-SY5Y cells. J Ethnopharmacol 135: 34-42, 2011.

25. Liao B, Newmark H and Zhou R: Neuroprotective effects of ginseng total saponin and ginsenosides Rb1 and Rg1 on spinal cord neurons in vitro. Exp Neurol 173: 224-234, 2002.

26. Jia RZ, Jiang L, Qiao LX and Chen PS: Neuroprotective effects of Astragulus membranaceus on hypoxia-ischemia brain damage in neonatal rat hippocampus. Zhongguo Zhong Yao Za Zhi 28: 1174-1177, 2003

27. Nie RQ, Li KH, Hu GZ, Zhang J, Wen Z, Wu DF and Yang XY: Study of the influence of Ginsenoside Rb1 on apoptosis of primary cultured neonate rat cerebral cortical neurons caused by hypoxia. Chin Rehab Theo Prac 10: 723-725, 2004 (In Chinese).

28. Hu GZ, Qi QY, Gao YQ and Wen Z: Study of mechanism of Panax quinquefolium L. saponin suppressing neurons apoptosis induced by anoxia. Pharma Clin Chin Mat Med 28: 57-61, 2012 (In Chinese).

29. Nie RQ, Li KH, Hu GZ, Zhang J, Wen Z, Wu DF and Yang XY: Study of the influence of Huangqi on the apoptosis of primary cultured neonate rat cerebral cortical neurons caused by hypoxia in vitro. Chin Bas Med Tradi Chin Med 10: 34-37, 2004 (In Chinese). 